\title{
Volatile Fatty Acids Production from Codigestion of Food Waste and Sewage Sludge Based on $\beta$-Cyclodextrins and Alkaline Treatments
}

\author{
Xue Yang, ${ }^{1,2}$ Xiang Liu, ${ }^{3}$ Si Chen, ${ }^{3}$ Guangmin Liu, ${ }^{4}$ Shuyan $W u,{ }^{5}$ and Chunli Wan ${ }^{3}$ \\ ${ }^{1}$ Postdoctoral Research Station of Civil Engineering, Tongji University, Siping Road, Shanghai 200092, China \\ ${ }^{2}$ State Key Laboratory of Pollution Control and Resources Reuse, College of Environmental Science and Engineering, \\ Tongji University, Shanghai 200092, China \\ ${ }^{3}$ Department of Environmental Science and Engineering, Fudan University, Handan Road, Shanghai 200433, China \\ ${ }^{4}$ College of Materials Science and Chemical Engineering, Harbin Engineering University, Nantong Street, Harbin 150001, China \\ ${ }^{5}$ China Nerin Engineering Co., Ltd., Hainan Branch Company, Jinmao West Road, Hainan 570100, China
}

Correspondence should be addressed to Guangmin Liu; liuguangmin@vip.sina.com and Chunli Wan; hitwan@163.com

Received 18 May 2016; Accepted 19 June 2016

Academic Editor: William B. Whitman

Copyright (C) 2016 Xue Yang et al. This is an open access article distributed under the Creative Commons Attribution License, which permits unrestricted use, distribution, and reproduction in any medium, provided the original work is properly cited.

\begin{abstract}
Volatile fatty acids (VFAs) are preferred valuable resources, which can be produced from anaerobic digestion process. This study presents a novel technology using $\beta$-cyclodextrins $(\beta-C D)$ pretreatment integrated alkaline method to enhance VFAs production from codigestion of food waste and sewage sludge. Experiment results showed that optimized ratio of food waste to sewage sludge was $3: 2$ because it provided adequate organic substance and seed microorganisms. Based on this optimized ratio, the integrated treatment of alkaline $\mathrm{pH} 10$ and $\beta$-CD addition $(0.2 \mathrm{~g} / \mathrm{g}$ TS) performed the best enhancement on VFAs production, and the maximum VFAs production was $8631.7 \mathrm{mg} / \mathrm{L}$ which was $6.13,1.38$, and 1.57 times higher than that of control, initial $\mathrm{pH} 10$, and $0.2 \mathrm{~g} \beta$-CD/g TS treatment, respectively. Furthermore, the hydrolysis rate of protein and polysaccharides was greatly improved in integration treatment, which was 1.18-3.45 times higher than that of other tests. Though the VFAs production and hydrolysis of polymeric organics were highly enhanced, the primary bacterial communities with different treatments did not show substantial differences.
\end{abstract}

\section{Introduction}

Food waste (FW) is becoming a serious concern for the developed countries due to its environmental impacts. About $6.0 \times 10^{7}$ tons of FW were produced according to China Statistical Yearbook 2011, and the increasing rate of FW production was higher than $10 \%$ every year due to population growth and rising living standards. In addition, as the byproduct of wastewater treatment plants (WWTPs), 6.25 million tons of dry excess sludge has been produced in China in 2013 and is still showing a rapid increasing rate [1]. The excess sludge disposal has been considered as a main issue for the sustainable development of WWTPs because the cost of efficient WAS disposal is very high, accounting for approximately $40-60 \%$ operation fee of WWTPs $[1,2]$. As well known, the main component of food waste and excess sludge is organic matter (e.g., proteins, polysaccharides, and lipid), and anaerobic digestion is preferred as an efficient pathway for treatment of these highly organic solids [3]. Efficient digestion of such organics can generate soluble organic products that assist in recovery of valuable resources [4]. Volatile fatty acids were valuable products as alternative carbons for nutrients removal, polyhydroxyalkanoates (PHA) production, and methane production processes [5-7].

Generally, anaerobic digestion process of particulate organic matter usually includes three stages: hydrolysis, acidification, and methanogenesis. Hydrolysis is known as the rate-limiting step. And only little of organic carbons can be biodegraded unless the particulate organic matter is significantly solubilized $[8,9]$. Aiming at strengthening 
the performance of anaerobic digestion, some efforts have been developed, such as chemical, mechanical, biological, and thermal cofermentation treatments [10-14]. Alkaline treatment has been selected as a potential way for improving volatile fatty acids (VFAs) production and also affected the composition of hydrolysate, hence leading to distinct VFAs composition in the subsequent fermentation process [15]. However, though the VFAs production can be improved at $\mathrm{pH} 10$, more than $60 \%$ of volatile suspended solids (VSS) could not be effectively degraded $[15,16]$. Thus, it is necessary to study other methods to assist in alkaline pretreatment to further enhance VSS destruction and further harvest VFAs.

Some studies recently reported that surfactant can improve particulate organic matter dissolution and inhibit methanogenesis, which in turn benefitted VFAs production $[17,18]$. Chemically synthesized surfactants (e.g., sodium dodecyl sulfate and sodium dodecyl benzenesulfonate) were firstly noted to improve the efficiency of anaerobic fermentation, but the residues present a potential risk to the ecosystem due to their biotoxicity $[8,11]$. A typical $\beta$-cyclodextrin $(\beta$ CD) molecule has seven glucose monomers linked in a ring by $\alpha$-1,4-glycosidic bonds [19], which could form host-guest complexes with hydrophobic molecules to enhance pollutant removal [20]. Compared with other chemical solubilizers, $\beta$ $\mathrm{CD}$ has low biologic toxicity and low potential to produce secondary pollutants [21]. Furthermore, our previous study approved that $\beta$-CD could enhance the hydrolysis rates of sewage sludge and inhibited activities of methanogens to maximize VFAs production [11].

The main objective of this study is to evaluate the feasibility of $\beta$-CD addition integrated into alkaline pretreatment for enhancing VFAs production from codigestion of food waste and sewage sludge. The mechanisms of integrated method for enhancing VFAs production were investigated by analyzing extracellular polymeric substances (EPS) and kinetic model of hydrolysis. Meanwhile, the bacterial communities of codigestion of FW and SS were studied to understand the codigestion of FW and SS based on the integrated treatment.

\section{Methods and Materials}

2.1. Food Waste and Sludge Inoculum. FW was collected daily from the cafeteria of a university located in Harbin (China). Grease was discarded through washing the FW for 3-4 times, and FW was crushed to particle size of $3-5 \mathrm{~mm}$. SS was sampled from a municipal wastewater treatment plant in Harbin, China. The SS was firstly thickened by gravitational sedimentation for $24 \mathrm{~h}$ at $4^{\circ} \mathrm{C}$ and then screened to remove impurities. Finally, the FW and SS were stored at $4^{\circ} \mathrm{C}$ before use. The basic characteristics of FW and SS were listed in Table 1.

2.2. Batch Experiments for VFAs Production. Firstly, the optimized ratio of food waste (FW) to sewage sludge (SS) for VFAs production was determined. According to total solid (TS) listed in Table 1, the FW-to-SS ratios were $1: 1,2: 1,3: 2$, and $2: 3$, adjusting the final TS to $30 \pm 0.5 \mathrm{~g} / \mathrm{L}$. Furthermore, the optimized dosage of $\beta$-CD for VFAs production was studied on the basis of the optimized ratio of FW to SS, and
TABLE 1: The characteristics of food waste and feed sludge for anaerobic codigestion.

\begin{tabular}{lcc}
\hline Characters & Food waste & Sewage sludge \\
\hline Total solids $(\mathrm{g} / \mathrm{L})$ & $31.23 \pm 0.43$ & $29.72 \pm 0.47$ \\
Volatile solids $(\mathrm{g} / \mathrm{L})$ & $30.34 \pm 0.38$ & $23.67 \pm 0.31$ \\
VFAs $(\mathrm{mg} / \mathrm{L})$ & $17.55 \pm 3.81$ & $64.19 \pm 7.61$ \\
\hline
\end{tabular}

five parallel tests were conducted with $\beta$-CD addition in the range of $0-0.2 \mathrm{~g} / \mathrm{g}$ TS. The $\mathrm{pH}$ was not adjusted in the above two tests. Then, to investigate the effects of alkaline $\mathrm{pH}$, sole $\beta-\mathrm{CD}$, and integrated treatments on VFAs production from FW and SS mixture, six parallel tests were carried out. The mixture without any pretreatments was adopted as control test $(\mathrm{CK})$. Batch tests were conducted in $1 \mathrm{~L}$ serum bottles filled with $800 \mathrm{~mL}$ mixture of FW and SS. Based on the online $\mathrm{pH}$ monitor, the demanded $\mathrm{pH}$ was automatically pumped into the bottles by adding $4 \mathrm{M} \mathrm{NaOH}$ and $1 \mathrm{M} \mathrm{HCl}$. The headspaces were flushed with nitrogen gas for 3-5 min to remove oxygen. Then the bottles were incubated in an air-bath shaker $(120 \mathrm{rpm})$ at $35 \pm 0.5^{\circ} \mathrm{C}$ for 8 days. All the experiments were carried out in triplicate.

2.3. Kinetics Modeling. Pseudo-first-order (PFO) model was applied to understand the effects of sole or combined treatments on hydrolysis of polymeric substance during codigestion of FW and SS. The PFO model could be determined by the following equation:

$$
\ln \left(C_{e}-C_{t}\right)=\ln C_{e}-k t
$$

where $C_{t}$ represents the concentration of protein/polysaccharides at time $t(\mathrm{~h}), C_{e}$ represents the relative equilibrium capacity of protein/polysaccharides, and $k\left(\mathrm{~h}^{-1}\right)$ represents the rate constant of PFO model.

The normalized standard deviation (NSD, $\Delta q(\%))$ and average relative error (ARE $(\%)$ ), calculated by the following equation, were employed to evaluate the error of PFO model $[22,23]:$

$$
\begin{aligned}
\operatorname{ARE}(\%) & =\frac{100}{N-1} \sum_{i=1}^{N}\left(\frac{C_{t, \exp }-C_{t, \mathrm{cal}}}{C_{t, \exp }}\right)_{i}^{2} \\
\Delta q(\%) & =100 \sqrt{\frac{1}{N-1} \sum_{i=1}^{N}\left(\frac{C_{t, \exp }-C_{t, \mathrm{cal}}}{C_{t, \exp }}\right)_{i}^{2}},
\end{aligned}
$$

where $C_{t, \exp }$ and $C_{t, \mathrm{cal}}$ represent the experimental and calculated values, respectively, at time $t$ and $N$ was the number of measurements made.

2.4. Bacterial Community Analysis. The total DNA $(100 \mu \mathrm{L})$ of samples collected from batch tests was extracted using MoBio PowerSoil DNA Isolation Kit (Mo-Bio Laboratories, Inc., USA) according to the manufacturer's protocol. The genomic DNA was evaluated by electrophoresis in $1 \%$ agarose gels.

The PCR procedures were referred to in Wan et al. [24] and the mixture $(50 \mu \mathrm{L})$ consisted of the following: $5 \mu \mathrm{L}$ 
of 10x PCR buffer, $0.5 \mu \mathrm{L}$ of dNTP (10 mM each), $10 \mathrm{ng}$ of genomic DNA, $1 \mu \mathrm{L}$ of Bar-PCR primer $\mathrm{F}(50 \mu \mathrm{M}), 1 \mu \mathrm{L}$ of primer $\mathrm{R}(50 \mu \mathrm{M}), 0.5 \mu \mathrm{L}$ of Platinum Taq $(5 \mathrm{U} / \mu \mathrm{L})$, and sterile $\mathrm{ddH}_{2} \mathrm{O}$ to a final volume of $50 \mu \mathrm{L}$. For the following high-throughput sequencing, the PCR primers were BarPCR primer F (CGTATCGCCTCCCTCGCGCCATCAG + BACODE + AGRGTTYGATYMTGGCTCAG) and primer R (CTATGCGCCTTGCCAGCCCGCTCAG + ACCGCGGCKGCTGGC). The PCR conditions were as follows: $94^{\circ} \mathrm{C}$ for $10 \mathrm{~min} ; 5$ cycles consisting of $94^{\circ} \mathrm{C}$ for $20 \mathrm{~s}, 45^{\circ} \mathrm{C}$ for $20 \mathrm{~s}$, and $65^{\circ} \mathrm{C}$ for $60 \mathrm{~s} ; 20$ cycles consisting of $94^{\circ} \mathrm{C}$ for $20 \mathrm{~s}, 60^{\circ} \mathrm{C}$ for $20 \mathrm{~s}$, and $72^{\circ} \mathrm{C}$ for $20 \mathrm{~s}$; and a final step of $10 \mathrm{~min}$ at $72^{\circ} \mathrm{C}$. The PCR products were evaluated using $1 \%$ agarose gels. The PCR products were further purified using a DNA gel extraction kit (Sangon Biotech Co., Ltd., Shanghai, China). Then, the extracted PCR products were quantified using Qubit 2.0 kit. Finally, all the PCR products were doubly diluted by sterile $\mathrm{ddH}_{2} \mathrm{O}$.

The ROCHE Emulsion-PCR technology was adopted to prepare single-molecule PCR product. Emulsion-PCR (ePCR) mixture could integrate PCR aqueous phase with oil phase. Each mixed droplet contained one molecule of DNA, magnetic bead, and PCR reaction mixture. Therefore, PCR bias can be effectively reduced due to the efficient amplification of one molecule of bacterial DNA. Finally, the genomic samples were taken for high-throughput sequenced by Ion Torrent PGM (Life Technologies, USA).

2.5. Analytical Methods. Collected samples were firstly centrifuged at 10,000 rpm for $10 \mathrm{~min}$; then supernatant samples were filtered by $0.45 \mu \mathrm{m}$ membrane filters and finally filtrated samples were stored at $4^{\circ} \mathrm{C}$ prior to analysis. The filtrate was immediately used to analyze VFAs, polysaccharides, and proteins. The measurements of VFAs, SCOD, TCOD, polysaccharides, and proteins were the same as the methods mentioned in previous publications $[8,25,26]$. The VFAs were regarded as the sum of acetic (HAc), propionic (HPr), $n$-butyric $(n-\mathrm{HBu})$, iso-butyric (iso-HBu), n-valeric (n-HVa), and isovaleric acids (iso-HVa) [11].

\section{Results and Discussion}

\subsection{Performances of VFAs Production from Codigestion of FW and SS}

3.1.1. Optimized FW-to-SS Ratio for VFAs Production. In order to determine the optimized ratio of FW and SS for VFAs production, five ratios of FW and SS $(1: 1,2: 1,3: 2,2: 3$, and 1:2) (TS) were conducted (Figure 1). The highest VFAs $(1401.4 \mathrm{mg} / \mathrm{L})$ at the end of cofermentation were obtained at the ratio of $3: 2$ (TS), followed by $1337.4 \mathrm{mg} / \mathrm{L}$ of VFAs at ratio of $2: 1$. Then, the VFAs production at ratios of $2: 3$ and $1: 1$ was almost the same (1277.4 versus $1237.9 \mathrm{mg} / \mathrm{L})$, which were both higher than the test at ratio of $1: 2(1014.7 \mathrm{mg} / \mathrm{L})$. Although the TS in all tests was around $30 \mathrm{~g} / \mathrm{L}$, more FW addition brought more VFAs. The food waste contained more easily biodegradable substances than sewage sludge, and sludge provided microorganisms to degrade these polymeric

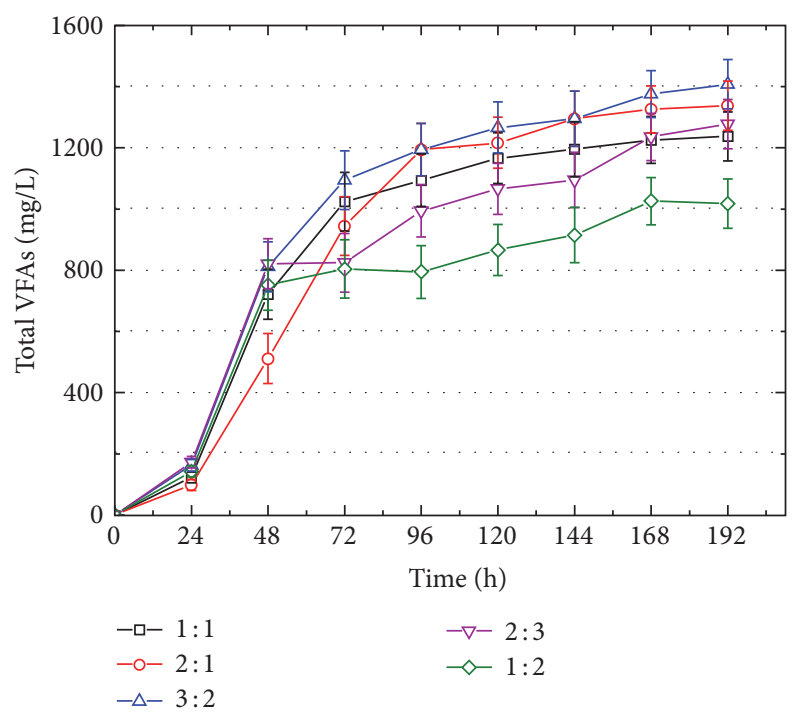

FIGURE 1: Performances of VFAs production from codigestion of FW and SS at different ratios.

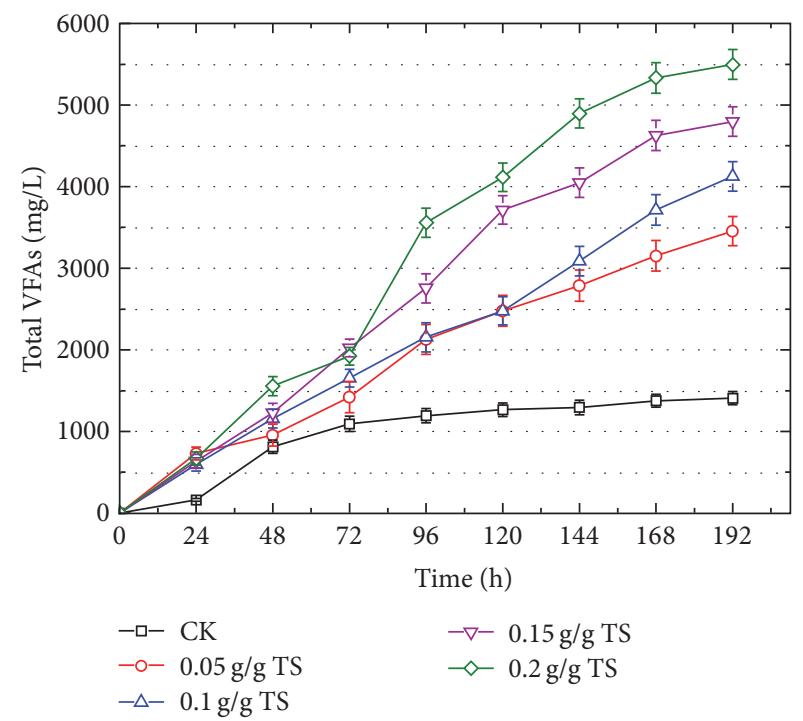

FIGURE 2: Effects of $\beta$-CD dosage (including $0.05,0.1,0.15$, and $0.2 \mathrm{~g}$ $\beta-\mathrm{CD} / \mathrm{g}$ total solid (TS)) on total VFAs production from mixture of FW and SS at ratio of $3: 2$. The test without $\beta$-CD addition was set as control test (CK).

organics. Thus, more food waste addition brought VFAs production. And, higher VFAs yield at ratio of $3: 2$ than $2: 1$ suggests that adequate sludge was also necessary for VFAs production.

3.1.2. Effects of Different $\beta$-CD Dosages on VFAs Production. As shown in Figure 2, it was clear that the $\beta$-CD addition improved VFAs production with all ranges of $\beta$-CD dosages. The minimal $\beta$-CD addition $(0.05 \mathrm{~g} / \mathrm{g}$ TS) obtained $3456.1 \mathrm{mg} / \mathrm{L}$ of VFAs, which was 2.46 times than that of control test. With the increase in $\beta$-CD addition, more VFAs were accumulated at the end of fermentation, and 4126.9 


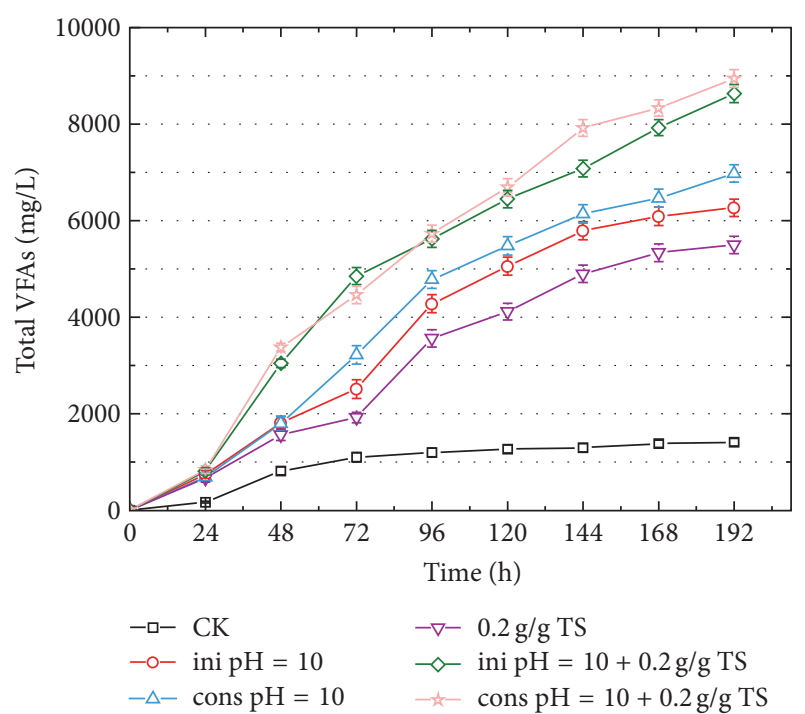

FIGURE 3: Effects of alkaline $\mathrm{pH} 10, \beta-\mathrm{CD}$ addition, and combined treatment on VFAs production from codigestion of FW and SS $(3: 2)$. The $\mathrm{pH}$ control was divided into initial $\mathrm{pH} 10$ adjustment (ini $\mathrm{pH}=10$ ) and constant $\mathrm{pH} 10$ adjustment (cons $\mathrm{pH}=10$ ). The $\beta$-CD dosage was $0.2 \mathrm{~g} / \mathrm{g}$ total solid (TS).

and $4796.9 \mathrm{mg} / \mathrm{L}$ of VFAs were, respectively, obtained with $0.1 \mathrm{~g} / \mathrm{g}$ TS and $0.15 \mathrm{~g} / \mathrm{g}$ TS $\beta$-CD addition. The maximal VFAs production was achieved with $0.2 \mathrm{~g} / \mathrm{g}$ TS addition, which was 3.9 times higher than that obtained in control test. It was interesting that VFAs production did not show substantial differences with different $\beta$-CD addition during the first $72 \mathrm{~h}$ but indicated obvious increasing during the last days. $\beta$-CD is comprised of $7 \alpha$-D-glucopyranoside units and has hydrophobic groups inside and hydrophilic group outside, and the cavity of $\beta$-CD is $6.0-6.5 \times 7.9 \AA$. It can enhance solubility of hydrophobic compounds with smaller molecules than the cavity of $\beta$-CD, which in turn solubilize the particulate organic substance in this study [11]. Due to the adhesive characters of EPS, the sewage sludge or food waste has enormous aggregated molecules. Along with microbial metabolism, the enormous extracellular aggregates were broken into pieces, and then the polymers deserved solubilization by $\beta$-CD. Thus, if other more aggressive treatments could be synchronously adopted with $\beta$-CD addition, the acclimation phase might be shortened.

\subsubsection{Effects of Different Treatments on VFAs Production.} Previous studies have reported that VFAs production from sewage sludge could be obviously enhanced either by adopting an initial $\mathrm{pH} 10$ or by controlling $\mathrm{pH}$ at constant 10 [15]. This study compared the effects of these two alkaline conditions on VFAs production from codigestion of FW and SS. As shown in Figure 3, the VFAs production at initial pH 10 was $6262.3 \mathrm{mg} / \mathrm{L}$, which was 4.45 times higher than that obtained in control test, indicating the potential application of initial $\mathrm{pH} 10$ for VFAs production from FW and SS fermentation. And the VFAs production at the end of fermentation was $6971.3 \mathrm{mg} / \mathrm{L}$, which was 1.11 times higher than

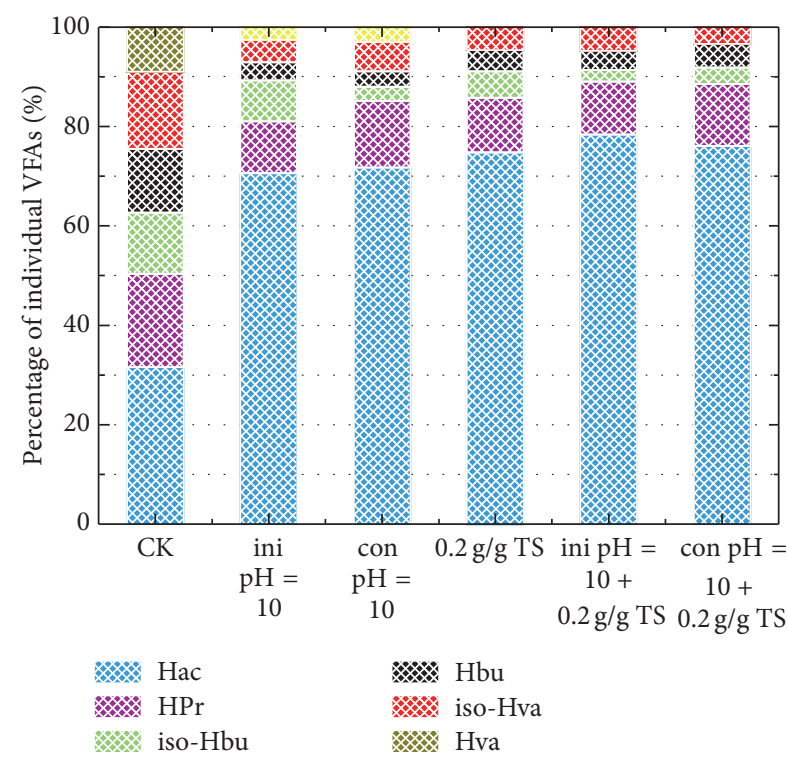

FIGURE 4: Composition of VFAs from codigestion of FW and SS $(3: 2)$ with different treatments at $8 \mathrm{~d}$. The $\mathrm{pH}$ control was divided into initial $\mathrm{pH} 10$ adjustment (ini $\mathrm{pH}=10$ ) and constant $\mathrm{pH} 10$ adjustment (cons $\mathrm{pH}=10$ ). The $\beta$-CD dosage was $0.2 \mathrm{~g} / \mathrm{g}$ total solid (TS). The mixture of FW and SS without any treatment was set as control test (CK).

that under initial $\mathrm{pH} 10$. The analogous results were obtained at combined treatments of initial/constant $\mathrm{pH} 10$ with $0.2 \mathrm{~g}$ $\beta-\mathrm{CD} / \mathrm{g}$ TS, which, respectively, produced $8631.7 \mathrm{mg} / \mathrm{L}$ (ini $\mathrm{pH} 10+0.2 \mathrm{~g} / \mathrm{g}$ TS) and $8943.1 \mathrm{mg} / \mathrm{L}$ (cons $\mathrm{pH} 10+0.2 \mathrm{~g} / \mathrm{g}$ TS). Despite higher VFAs production with constant $\mathrm{pH} 10$, constant alkaline chemical addition was neither economic nor convenient for organic wastes disposal. Furthermore, it was obvious that VFAs production was promoted by sole $\beta$-CD addition, which was 3.9 times higher than that of control test. However, the VFAs production by sole $\beta$-CD addition was lower than that obtained by sole alkaline $\mathrm{pH} 10$, which might be due to the gentler solubilization of organic substances by $\beta$-CD than by alkaline $\mathrm{pH}$. But, considering the corrosion of pipes or equipment by external regents, $\beta$-CD addition was more promising than alkaline treatments.

3.1.4. Composition of VFAs with Different Treatments. The composition of VFAs would influence the further application of fermentation liquid, such as external carbon source for nutrient removal [27]. It was observed that the composition of VFAs was significantly affected by alkaline $\mathrm{pH}$ and $\beta$ $\mathrm{CD}$ addition. For all the tests, HAc and HPr were the two highest individual VFAs with a total percentage of $81.1 \%$ $89.0 \%$, which was $1.61-1.77$ times higher than that of control test (Figure 4). The order of percentage of individual VFAs was $\mathrm{HAc}>\mathrm{HPr}>\mathrm{Hbu}>\mathrm{Hva}$. The possible reasons were that HAc and HPr were directly from the fermentation of organic polymers [26], and higher molecular weight VFAs such as Hva or Hbu were easily biodegraded to form HAc in anaerobic fermentation system $[15,27]$. 


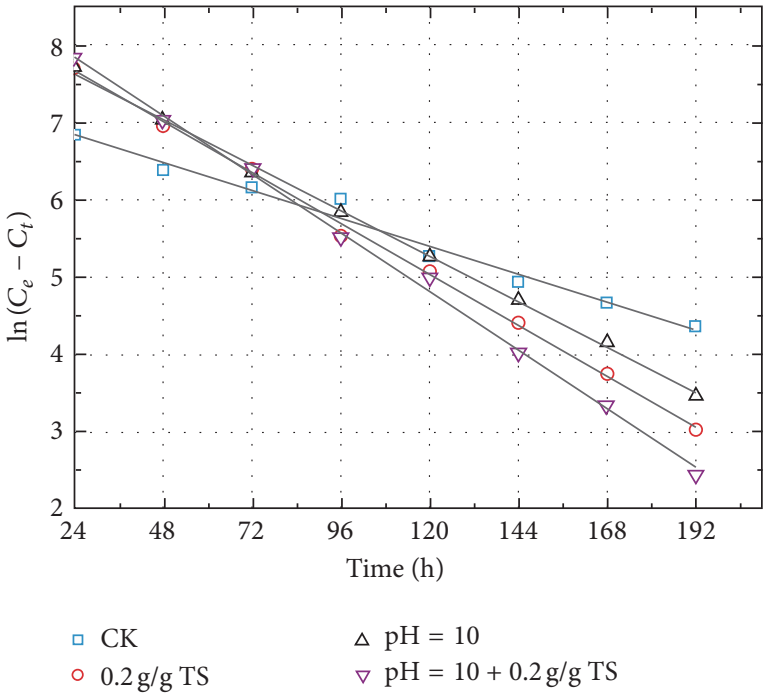

(a)

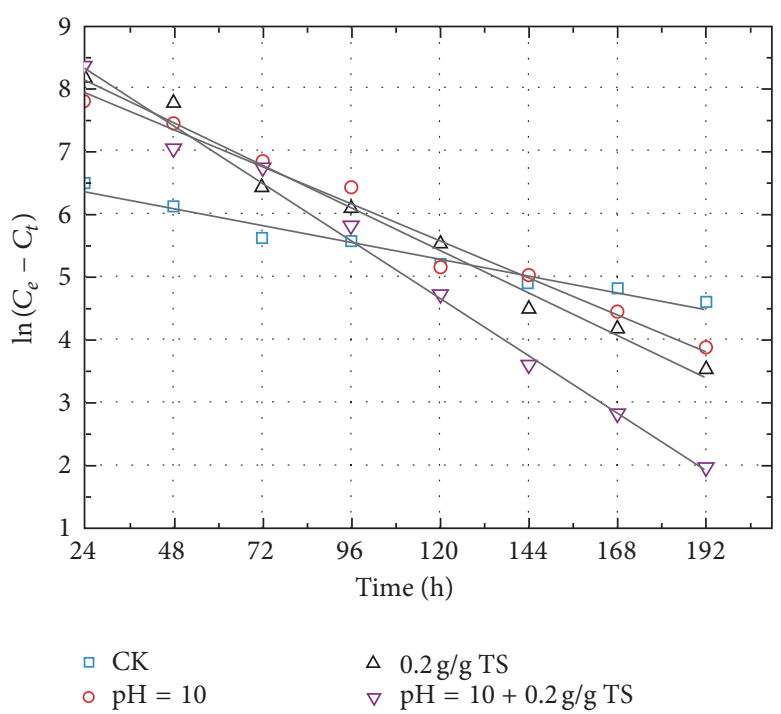

(b)

FIGURE 5: Kinetic modeling of hydrolysis of FW and SS based on different treatments. (a) and (b), respectively, represent kinetic analysis of protein and polysaccharides. The $\mathrm{pH}$ control was initial $\mathrm{pH} 10$ adjustment. The $\beta$-CD dosage was $0.2 \mathrm{~g} / \mathrm{g}$ total solid (TS). The mixture of FW and SS without any treatment was set as control test (CK).

\subsection{Mechanisms of VFAs Production Based on Combined Treatments}

3.2.1. Kinetic Modeling of Hydrolysis of Polymeric Substances. As the VFAs production by constant $\mathrm{pH} 10$ did not indicate much more advantages than by initial $\mathrm{pH} 10$, thus in the mechanisms of VFAs production was only investigated in initial $\mathrm{pH} 10$ tests. The levels of soluble protein and polysaccharides could be taken as an index to evaluate the efficiency of hydrolysis. Thus, the released proteins/polysaccharides were fitted using PFO model, evaluating the hydrolysis of polymeric substances during codigestion of FW and SS. Figures 5(a) and 5(b) indicate the hydrolysis kinetics of FW and SS based on sole and combined treatments. It was obvious that good agreement was achieved between calculated and experimental results, with strong correlation coefficients $\left(R^{2}\right.$ : $0.962-0.999)$, low $\operatorname{ARE}(\%)(0.024-0.900<1)$, and $\Delta q(\%)$ $(1.553-9.490<10)$ (Table 2$)$, suggesting that the hydrolysis of protein/polysaccharides from the mixture (FW and SS) obeyed the PFO model. In terms of sludge, both PFO and first-order models have been successfully used to fit the hydrolysis of polymeric substances $[15,28]$. The highest hydrolysis rate constants of protein and polysaccharides were obtained in combined tests, 2.13 (protein) and 3.45 (polysaccharides) times higher than control test. The sole $\mathrm{pH}$ 10.0 treatment took more obvious enhancement on hydrolysis of protein than that of polysaccharides, which was similar to the results of hydrolysis of sewage sludge [15]. Contrary to the protein, the polysaccharides deserved more obvious hydrolysis based on the sole $\beta$-CD treatment $(0.2 \mathrm{~g} / \mathrm{g}$ TS), which was mainly due to the analogous molecular structure of $\beta$-CD to polysaccharides. Furthermore, both alkaline and $\beta$-CD treatments boosted hydrolysis of protein and polysaccharides compared to control test.
3.2.2. Evolution of Bacterial Communities. Detailed evolution of bacterial communities was investigated to further find out the underlying mechanisms of the difference between the effects of alkaline $\mathrm{pH}$ and $\beta$-CD addition on anaerobic codigestion of FW and SS. After Chimer analysis, 33561, 37823, and 30222 reads were generated for further analysis. These high quality reads were assigned to different taxa levels using the RDP classifier. A total of 25 phyla were identified, and Proteobacteria, Bacteroidetes, Actinobacteria, and Firmicutes were the predominant phyla in bacterial community.

The top 10 abundant genera (Table 3 ) in each sample were selected for a detailed understanding of the evolution of microbial community structure as suggested previously [29]. Parabacteroides obviously increased from $0.15 \%$ in initial sludge to $17.37 \%-27.11 \%$ in all three tests and in turn became the predominant member in all three tests. It was more probably related to its function as a saccharolytic bacterium that produces acetate and succinate as primary fermentation end products [30]. Proteiniborus was the second predominant member in all three tests at the end of codigestion, which is usually recognized as protein-specific utilizing bacteria, and the fermentation products mainly include ethanol, acetic acid, hydrogen, carbon dioxide, and a trace amount of propionic acid [31]. Petrimonas increased with the fermentation time and showed highest abundance in integrated treatment test. Members belonging to this genus are mesophilic, strictly anaerobic, and fermentative bacteria, and acetic acid was the major end product [32]. Sporacetigenium was detected as main member in $\beta$-CD addition test but not abundant in alkaline $\mathrm{pH}$ and integrated experiments, which was mainly because it plays an important role in producing acetate and butyrate from glucose but cannot survive with strong alkaline pHs [33]. Butyrivibrio and Eubacterium were not 
TABLE 2: Kinetic parameters for hydrolysis based on different treatments.

\begin{tabular}{lcccccccc}
\hline & \multicolumn{4}{c}{ Hydrolysis of protein } & \multicolumn{4}{c}{ Hydrolysis of polysaccharides } \\
& $\mathrm{CK}$ & $\mathrm{pH}=10$ & $0.2 \mathrm{~g} / \mathrm{g}$ TS & $\mathrm{pH}=10+0.2 \mathrm{~g} / \mathrm{g} \mathrm{TS}$ & $\mathrm{CK}$ & $\mathrm{pH}=10$ & $0.2 \mathrm{~g} / \mathrm{g}$ TS & $\mathrm{pH}=10+0.2 \mathrm{~g} / \mathrm{g}$ TS \\
\hline$k_{1}\left(\mathrm{~h}^{-1}\right)$ & 0.015 & 0.027 & 0.025 & 0.032 & 0.011 & 0.024 & 0.028 & 0.038 \\
$C_{e}$ & 1421 & 3855 & 3058 & 4753 & 939 & 2857 & 3836 & 4664 \\
$R^{2}$ & 0.991 & 0.998 & 0.999 & 0.998 & 0.962 & 0.977 & 0.981 & 0.991 \\
$\Delta q(\%)$ & 2.314 & 1.758 & 2.212 & 1.553 & 8.973 & 9.490 & 8.461 & 9.097 \\
$\mathrm{ARE}(\%)$ & 0.049 & 0.031 & 0.049 & 0.024 & 0.805 & 0.900 & 0.715 & 0.827 \\
\hline
\end{tabular}

TABLE 3: Top 10 bacterial genera from codigestion of FW and SS $(3: 2)$ with different treatments at $3 \mathrm{~d}$ and $8 \mathrm{~d}$. Unclassified sequences were removed prior to the data analysis (\%, relative abundance).

\begin{tabular}{|c|c|c|c|c|c|c|c|}
\hline Genera & Initial & $\mathrm{pH} \mathrm{10/3d}$ & $\beta-\mathrm{CD} / 3 \mathrm{~d}$ & Integrated $/ 3 \mathrm{~d}$ & $\mathrm{pH} 10 / 8 \mathrm{~d}$ & $\beta-\mathrm{CD} / 8 \mathrm{~d}$ & Integrated $/ 8 \mathrm{~d}$ \\
\hline Parabacteroides & 0.15 & 19.60 & 17.37 & 23.98 & 24.32 & 21.29 & 27.11 \\
\hline Proteiniborus & 1.02 & 15.66 & 10.83 & 17.31 & 17.46 & 13.82 & 18.05 \\
\hline Petrimonas & 0.60 & 4.67 & 5.9 & 7.07 & 6.43 & 7.55 & 9.95 \\
\hline Sporacetigenium & 2.18 & 0.25 & 7.98 & 0.41 & 0.15 & 7.37 & 0.32 \\
\hline Butyrivibrio & 0.13 & 1.08 & 1.65 & 1.00 & 4.37 & 5.94 & 3.28 \\
\hline Eubacterium & 0.12 & 1.12 & 2.02 & 0.84 & 2.21 & 2.65 & 2.07 \\
\hline Propionibacterium & 0.33 & 0.67 & 0.90 & 0.43 & 0.41 & 0.55 & 0.73 \\
\hline Terrimonas & 0.41 & 0.84 & 0.72 & 0.32 & 0.45 & 0.35 & 0.81 \\
\hline Moorella & 0.31 & 0.59 & 0.61 & 0.88 & 0.76 & 0.74 & 1.33 \\
\hline Nitrospira & 0.12 & 0.44 & 0.32 & 0.33 & 0.61 & 0.67 & 0.35 \\
\hline
\end{tabular}

main members in bacterial samples at initial and $3 \mathrm{~d}$ but accumulated at the end of fermentation in all three tests. They belong to Clostridia, and the main members played an important role in butyric acid type fermentation [34]. This accumulation of Butyrivibrio and Eubacterium might be due to the acclimation of nutrient conditions. The other main coexisting bacteria included Propionibacterium, Terrimonas, Moorella, and Nitrospira. They survived in the whole codigestion process but did not become the primary ones in bacterial samples. The function of these coexisting bacteria was mainly VFAs production with propionic acid and acetic acid as fermentation products.

\section{Conclusions}

The feasibility of short-term codigestion for enhancing VFAs production from FW and SS with a novel proposed method, $\beta$-CD addition integrated into alkaline $\mathrm{pH} 10$, has been investigated in this work. The main conclusions are as follows. (1) Optimized ratio of FW to SS was 3:2 because the system could provide adequate organic substance and seed microorganisms. (2) Positive synergies on anaerobic codigestion were obtained. The maximum VFAs production was $8631.7 \mathrm{mg} / \mathrm{L}$ at the end of fermentation, when FW and SS were pretreated by initial $\mathrm{pH} 10$ and $\beta$-CD dosage of $0.2 \mathrm{~g} / \mathrm{g}$ TSS. (3) All the treatment methods ( $\mathrm{pH} 10, \beta-\mathrm{CD}$ addition, and integrated methods) could enhance the release EPS to suspension, and the highest hydrolysis rates for protein and polysaccharides were 0.032 and 0.038 (based on integrated method). (4) Primary bacterial communities based on each treatment did not show substantial difference, which are comprised of Parabacteroides, Proteiniborus, Petrimonas, and Sporacetigenium.

\section{Competing Interests}

The authors declare that they have no competing interests.

\section{Acknowledgments}

This work was financially supported by the National Natural Science Foundation of China (no. 51508398), China Postdoctoral Science Foundation Funded Project (no. 2015M571600), and Shanghai International Science and Technology Cooperation Fund (no. 14230700400).

\section{References}

[1] G. Yang, G. M. Zhang, and H. C. Wang, "Current state of sludge production, management, treatment and disposal in China," Water Research, vol. 78, pp. 60-73, 2015.

[2] C. Wu, G. M. Zhang, P. Y. Zhang, and C.-C. Chang, "Disintegration of excess activated sludge with potassium permanganate: feasibility, mechanisms and parameter optimization," Chemical Engineering Journal, vol. 240, pp. 420-425, 2014.

[3] Q. L. Wang, L. Ye, G. M. Jiang, P. D. Jensen, D. J. Batstone, and Z. Yuan, "Free nitrous acid (FNA)-based pretreatment enhances methane production from waste activated sludge," Environmental Science and Technology, vol. 47, no. 20, pp. 1189711904, 2013. 
[4] T.-W. Jan, S. S. Adav, D. J. Lee, R. M. Wu, A. Su, and J.-H. Tay, "Hydrogen fermentation and methane production from sludge with pretreatments," Energy and Fuels, vol. 22, no. 1, pp. 98-102, 2008.

[5] X. Li, H. Chen, L. Hu, L. Yu, Y. Chen, and G. Gu, "Pilotscale waste activated sludge alkaline fermentation, fermentation liquid separation, and application of fermentation liquid to improve biological nutrient removal," Environmental Science and Technology, vol. 45, no. 5, pp. 1834-1839, 2011.

[6] X. Yang, M. A. Du, D.-J. Lee, C. Wan, C. Chen, and F. Wan, "Enriching polyhydroxyalkanoates (PHA) producing microorganisms by complex organics from quickly alkaline fermentation liquor," Journal of the Taiwan Institute of Chemical Engineers, vol. 43, no. 6, pp. 953-957, 2012.

[7] D. Zhang, Y. G. Chen, Y. X. Zhao, and X. Y. Zhu, "New sludge pretreatment method to improve methane production in waste activated sludge digestion," Environmental Science and Technology, vol. 44, no. 12, pp. 4802-4808, 2010.

[8] A. J. Zhou, C. X. Yang, Z. C. Guo, Y. N. Hou, W. Z. Liu, and A. J. Wang, "Volatile fatty acids accumulation and rhamnolipid generation in situ from waste activated sludge fermentation stimulated by external rhamnolipid addition," Biochemical Engineering Journal, vol. 77, pp. 240-245, 2013.

[9] A. V. Ebenezer, P. Arulazhagan, S. A. Kumar, I.-T. Yeom, and J. R. Banu, "Effect of deflocculation on the efficiency of low-energy microwave pretreatment and anaerobic biodegradation of waste activated sludge," Applied Energy, vol. 145, pp. 104-110, 2015.

[10] X. Yang, M. A. Du, D.-J. Lee, C. L. Wan, L. N. Zheng, and F. Wan, "Improved volatile fatty acids production from proteins of sewage sludge with anthraquinone-2,6-disulfonate (AQDS) under anaerobic condition," Bioresource Technology, vol. 103, no. 1, pp. 494-497, 2012.

[11] X. Yang, M. Du, D.-J. Lee et al., "Enhanced production of volatile fatty acids (VFAs) from sewage sludge by $\beta$ cyclodextrin," Bioresource Technology, vol. 110, pp. 688-691, 2012.

[12] F. Morgan-Sagastume, S. Pratt, A. Karlsson, D. Cirne, P. Lant, and A. Werker, "Production of volatile fatty acids by fermentation of waste activated sludge pre-treated in full-scale thermal hydrolysis plants," Bioresource Technology, vol. 102, no. 3, pp. 3089-3097, 2011.

[13] Q. Yang, K. Luo, X.-M. Li et al., "Enhanced efficiency of biological excess sludge hydrolysis under anaerobic digestion by additional enzymes," Bioresource Technology, vol. 101, no. 9, pp. 2924-2930, 2010.

[14] P. A. Vesilind, S. Wallinmaa, and C. J. Martel, "Freeze-thaw sludge conditioning and double layer compression," Canadian Journal of Civil Engineering, vol. 18, no. 6, pp. 1078-1083, 1991.

[15] H. Y. Yuan, Y. G. Chen, H. X. Zhang, S. Jiang, Q. Zhou, and G. W. Gu, "Improved bioproduction of short-chain fatty acids (SCFAs) from excess sludge under alkaline conditions," Environmental Science and Technology, vol. 40, no. 6, pp. 20252029, 2006.

[16] J. W. Zhao, D. B. Wang, X. M. Li et al., "Free nitrous acid serving as a pretreatment method for alkaline fermentation to enhance short-chain fatty acid production from waste activated sludge," Water Research, vol. 78, pp. 111-120, 2015.

[17] S. Jiang, Y. Chen, and Q. Zhou, "Effect of sodium dodecyl sulfate on waste activated sludge hydrolysis and acidification," Chemical Engineering Journal, vol. 132, no. 1-3, pp. 311-317, 2007.

[18] X. F. Huang, C. M. Shen, J. Liu, and L. J. Lu, "Improved volatile fatty acid production during waste activated sludge anaerobic fermentation by different bio-surfactants," Chemical Engineering Journal, vol. 264, pp. 280-290, 2015.

[19] S.-O. Ko, M. A. Schlautman, and E. R. Carraway, "Partitioning of hydrophobic organic compounds to hydroxypropyl- $\beta$ cyclodextrin: experimental studies and model predictions for surfactant- enhanced remediation applications," Environmental Science and Technology, vol. 33, no. 16, pp. 2765-2770, 1999.

[20] D. Shao, G. Sheng, C. Chen, X. Wang, and M. Nagatsu, "Removal of polychlorinated biphenyls from aqueous solutions using $\beta$-cyclodextrin grafted multiwalled carbon nanotubes," Chemosphere, vol. 79, no. 7, pp. 679-685, 2010.

[21] C. L. Wan, M. A. Du, D.-J. Lee, X. Yang, W. C. Ma, and L. $\mathrm{N}$. Zheng, "Electrokinetic remediation and microbial community shift of $\beta$-cyclodextrin-dissolved petroleum hydrocarboncontaminated soil," Applied Microbiology and Biotechnology, vol. 89, no. 6, pp. 2019-2025, 2011.

[22] S. J. Allen, G. Mckay, and J. F. Porter, "Adsorption isotherm models for basic dye adsorption by peat in single and binary component systems," Journal of Colloid and Interface Science, vol. 280, no. 2, pp. 322-333, 2004.

[23] A. M. El-Kamash, A. A. Zaki, and M. A. El Geleel, "Modeling batch kinetics and thermodynamics of zinc and cadmium ions removal from waste solutions using synthetic zeolite A," Journal of Hazardous Materials, vol. 127, no. 1-3, pp. 211-220, 2005.

[24] C. L. Wan, S. Chen, L. Wen, D.-J. Lee, and X. Liu, "Formation of bacterial aerobic granules: role of propionate," Bioresource Technology, vol. 197, pp. 489-494, 2015.

[25] O. H. Lowry, N. J. Rosebrough, A. L. Farr, and R. J. Randall, "Protein measurement with the Folin phenol reagent," The Journal of Biological Chemistry, vol. 193, no. 1, pp. 265-275, 1951.

[26] D. Herbert, P. J. Philipps, and R. E. Strange, "Carbohydrate analysis," Methods in Enzymology, vol. 5, pp. 265-277, 1971.

[27] X. Yang, C. Wan, D.-J. Lee, M. Du, X. Pan, and F. Wan, "Continuous volatile fatty acid production from waste activated sludge hydrolyzed at pH 12," Bioresource Technology, vol. 168, pp. 173-179, 2014.

[28] Z.-W. He, C.-X. Yang, L. Wang, Z.-C. Guo, A.-J. Wang, and W.-Z. Liu, "Feasibility of short-term fermentation for shortchain fatty acids production from waste activated sludge at initial pH10: role and significance of rhamnolipid," Chemical Engineering Journal, vol. 290, pp. 125-135, 2016.

[29] J. Zhang, X. Cai, L. Qi et al., "Effects of aeration strategy on the evolution of dissolved organic matter (DOM) and microbial community structure during sludge bio-drying," Applied Microbiology and Biotechnology, vol. 99, no. 17, pp. 7321-7331, 2015.

[30] H.-Q. Tan, T.-T. Li, C. Zhu, X.-Q. Zhang, M. Wu, and X.-F. Zhu, "Parabacteroides chartae sp. nov., an obligately anaerobic species from wastewater of a paper mill," International Journal of Systematic and Evolutionary Microbiology, vol. 62, no. 11, pp. 2613-2617, 2012.

[31] L. Niu, L. Song, and X. Dong, "Proteiniborus ethanoligenes gen. nov., sp. nov., an anaerobic protein-utilizing bacterium," International Journal of Systematic and Evolutionary Microbiology, vol. 58, no. 1, pp. 12-16, 2008.

[32] A. Grabowski, B. J. Tindall, V. Bardin, D. Blanchet, and C. Jeanthon, "Petrimonas sulfuriphila gen. nov., sp. nov., a mesophilic fermentative bacterium isolated from a biodegraded oil reservoir," International Journal of Systematic and Evolutionary Microbiology, vol. 55, no. 3, pp. 1113-1121, 2005.

[33] S. L. Chen, L. Song, and X. Z. Dong, "Sporacetigenium mesophilum gen. nov., sp. nov., isolated from an anaerobic 
digester treating municipal solid waste and sewage," International Journal of Systematic and Evolutionary Microbiology, vol. 56, no. 4, pp. 721-725, 2006.

[34] C. Delbès, R. Moletta, and J.-J. Godon, "Bacterial and archaeal $16 \mathrm{~S}$ rDNA and $16 \mathrm{~S}$ rRNA dynamics during an acetate crisis in an anaerobic digestor ecosystem," FEMS Microbiology Ecology, vol. 35, no. 1, pp. 19-26, 2001. 

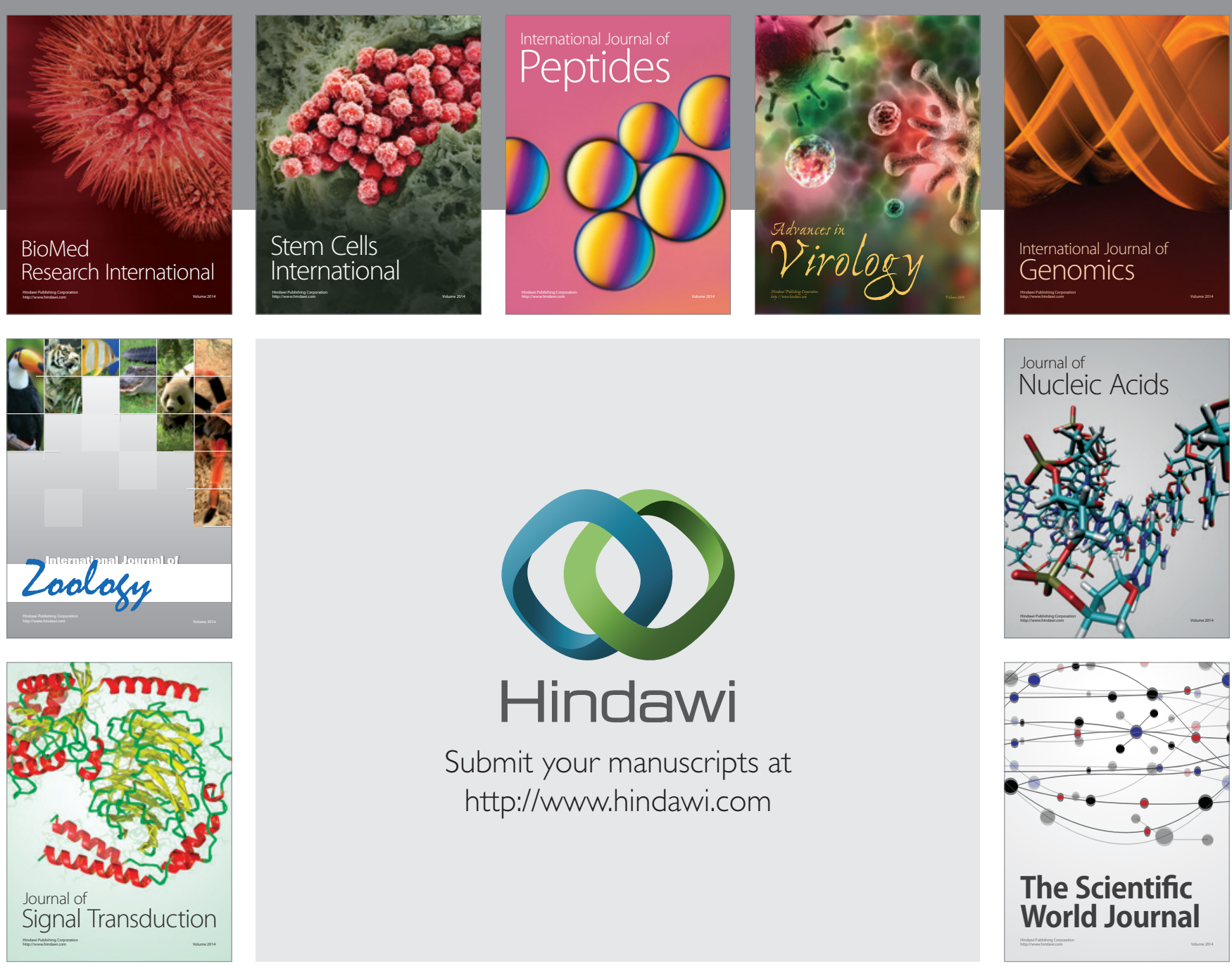

Submit your manuscripts at

http://www.hindawi.com
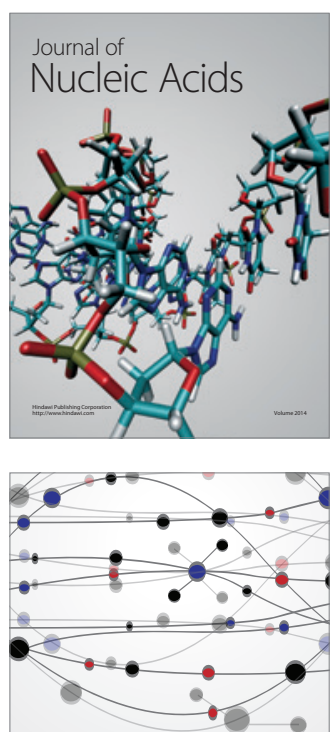

The Scientific World Journal
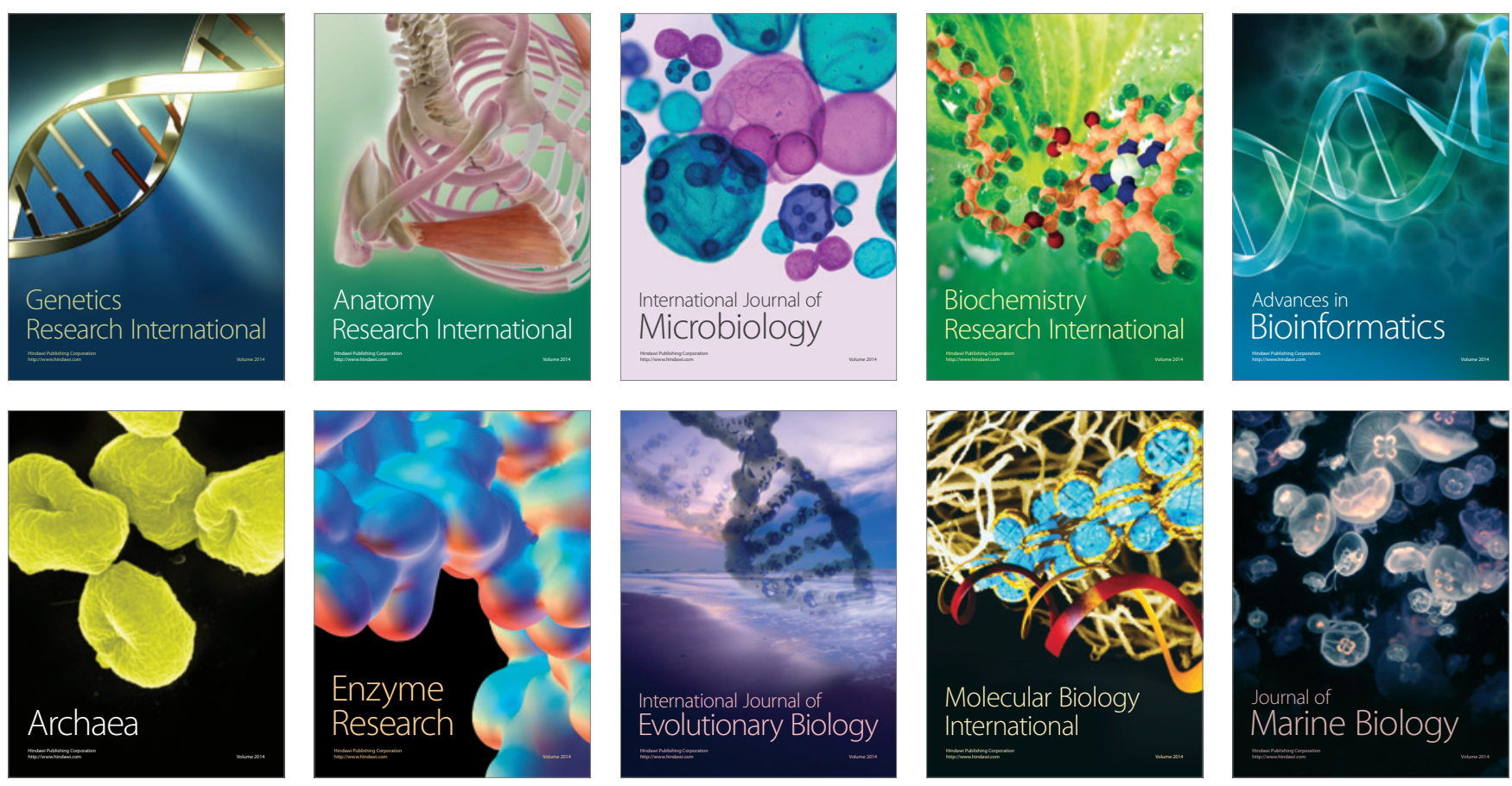